Article

\title{
Assessing the Potential of Multi-spectral and Multi-temporal Satellite Images for Classification and Mapping of Plant Communities in a Temperate Region
}

\author{
Ram C. Sharma ${ }^{1 *}$, Hidetake Hirayama$^{1}$, Masatsugu Yasuda $^{2}$, Itsuki Asai $^{2}$ and Keitarou Hara ${ }^{1}$
}

1 Department of Informatics, Tokyo University of Information Sciences, 4-1 Onaridai, Wakaba-ku, Chiba 265 8501, Japan; sharma@rsch.tuis.ac.jp, hh207501@rsch.tuis.ac.jp, hara@rsch.tuis.ac.jp

2 Asia Air Survey Co., Ltd., Kawasaki City, Kanagawa, Japan; mtg.yasuda@ajiko.co.jp, mk.asai@ajiko.co.jp

*Correspondence: ram-c-sha@pm.me; Tel.: +81-43-236-4603.

\begin{abstract}
Classification and mapping of plant communities is an essential step for conservation and management of ecosystems and biodiversity. We adopt the GenusPhysiognomy-Ecosystem (GPE) system developed in previous study for satellite-based classification of plant communities. This paper assesses the potential of multi-spectral and multi-temporal images collected by Sentinel-2 satellites. This research was conducted in five representative study sites in a temperate region. It consists of 44 types of plant communities including a few land cover types as well. The plant community types were enumerated in the study sites and ground truth data were prepared with reference to extant vegetation surveys, visual interpretation of high-resolution images, and onsite field observations. We acquired all Sentinel-2 Level-1C product images available for the study sites between 2017-2019 and generated monthly median composite images consisting of ten spectral and twelve spectral-indices. Gradient Boosting Decision Trees (GBDT) classifier was employed as an efficient and distributed gradient boosting technique for the supervised classification of big datasets involved in the research. The cross-validation accuracy in terms of kappa coefficient varied from $87 \%$ in Oze site with 41 land cover and plant community types to $95 \%$ in Hakkoda site with 19 land cover and plant community types; with average performance of $91 \%$ across all sites. In addition, the resulting maps demonstrated a clear distribution of plant community types involved in all sites, highlighting the potential of Sentinel-2 multi-spectral and multi-temporal images with GPE classification system for operational and broad-scale mapping of land cover and plant communities.
\end{abstract}

Keywords: Sentinel-2, Land cover, Vegetation, Mapping, Plant communities, Machine learning, Genus-Physiognomy-Ecosystem, Gradient Boosting Decision Trees

\section{Introduction}

Classification and mapping of plant communities is an essential step for conservation and management of ecosystems and biodiversity. In recent years, availability of free and open access data, high performance computing, and automated data processing and analysis capabilities have brought new opportunities for classification and mapping of plant communities from remotely sensed images (Murakami and Mochizuki, 2014; Wulder, 2018). In contrast to potential natural vegetation mapping based on climatic 
parameters available at coarse spatial resolution (Hengl et al., 2018), actual vegetation mapping (Bredenkamp et al., 1998; Su et al., 2020) with recently available satellite images can provide much detailed information at higher spatial resolution for improving the knowledge of plant community.

In Japan, a wide variety of land cover and plant communities, ranging from Southern Subtropical Forests to Northern Arctic Meadows, exists (Numata et al., 1972; Miyawaki, 1984; Himiyama, 1998). Nationwide vegetation surveys have been conducted continuously since 1973 and distribution of plant communities is well known. First vegetation survey of the entire country was completed in 1999 with the production of vegetation survey maps at 1:50,000 scale (MoE and AAS, 1999). Since 1999, extensive field surveys have been repeated and a 1:25,000 scale vegetation survey map is being produced nationwide (Hioki, 2007). The vegetation survey follows phyto-sociological units based organization plant communities (Miyawaki 1968; Ohno, 2006). The plant communities are recognized through field surveys and delineated in a geographical environment via a manual procedure facilitated by visual interpretation of aerial and satellite images. The manual delineation procedure is subject to human discernment, laborious, and costly. To cope with these issues, more intelligent technology has been expected.

The major objective of this paper is to assess the potential of multi-spectral and multitemporal images available from the Sentinel-2 mission satellites (Sentinel-2A and 2B) for operational and broad-scale mapping of land cover and plant community types by adopting the Genus-Physiognomy-Ecosystem (GPE) system developed in previous study for satellite-based classification of plant communities.

\section{Materials and Methods}

\subsection{Study sites}

This research was conducted in five representative sites of the Tohoku region in Japan. These five study sites were selected in such a way that they can represent all land cover and plant communities types present in the Tohoku region. The location map of five study sites has been shown in Figure 1.



Figure 1. The location of five study sites (Hakkoda, Oze, Zao, Shirakami, and Kitakami) are shown by blue rectangles in the Tohoku region of Japan (red polygon). 


\subsection{Preparation of ground truth data}

First of all, land cover and plant community types present in five study sites were enumerated by adopting the Genus-Physiognomy-Ecosystem (GPE) system developed in previous study (Sharma, 2021) for satellite-based classification and mapping of plant communities. Extant vegetation survey reports available from Nature Conservation Bureau, Ministry of the Environment and Asia Air Survey Co., Ltd were utilized as reference materials for enumerating land cover and plant community types in each study site. The land cover and plant community types were further verified by onsite field observations conducted between 2017 and 2020 in all study sites. The final confirmed list of land cover and plant community types present in five study sites has been described in Table 1.

Table 1. List of land cover and plant community types of Tohoku region enumerated in the research. The occurrence of land cover and plant community types in each study site are denoted by asterisk $\left({ }^{*}\right)$ symbol.

\begin{tabular}{|l|l|l|l|l|l|}
\hline Classes & Hakkoda & Oze & Zao & Shirakami & Kitakami \\
\hline Abies ECF & $*$ & $*$ & $*$ & & $*$ \\
\hline Acer DBF & & $*$ & $*$ & & \\
\hline Alnus DBF & $*$ & $*$ & $*$ & & $*$ \\
\hline Alpine Herb & & $*$ & $*$ & $*$ & $*$ \\
\hline Alpine Shrub & & & $*$ & & $*$ \\
\hline Bamboo EBF & & $*$ & & & $*$ \\
\hline Barren & $*$ & $*$ & $*$ & $*$ & $*$ \\
\hline Betula DBF & $*$ & $*$ & $*$ & $*$ & $*$ \\
\hline Carpinus DBF & & $*$ & & $*$ & $*$ \\
\hline Cryptomeria ECF & $*$ & $*$ & $*$ & $*$ & $*$ \\
\hline Euptelea DBF & & $*$ & & & \\
\hline Fagus DBF & $*$ & $*$ & $*$ & $*$ & $*$ \\
\hline Fraxinus DBF & & $*$ & & $*$ & $*$ \\
\hline Hydrangea Shrub & & $*$ & $*$ & & \\
\hline Juglans DBF & & $*$ & & $*$ & $*$ \\
\hline Larix DCF & $*$ & $*$ & $*$ & $*$ & $*$ \\
\hline Miscanthus Herb & $*$ & $*$ & $*$ & $*$ & $*$ \\
\hline Other Herb & $*$ & $*$ & $*$ & $*$ & \\
\hline Other Shrub & $*$ & $*$ & $*$ & & $*$ \\
\hline Paddy field & & $*$ & & $*$ & $*$ \\
\hline Pasture & $*$ & $*$ & & $*$ & $*$ \\
\hline Picea ECF & & & & & $*$ \\
\hline Pinus ECF & $*$ & $*$ & $*$ & $*$ & $*$ \\
\hline Pinus Shrub & $*$ & $*$ & $*$ & $*$ & $*$ \\
\hline Populus DBF & & $*$ & & & \\
\hline Pterocarya DBF & $*$ & $*$ & $*$ & $*$ & $*$ \\
\hline Quercus DBF & $*$ & $*$ & $*$ & $*$ & $*$ \\
\hline & & & & $*$ & \\
\hline
\end{tabular}




\begin{tabular}{|l|l|l|l|l|l|}
\hline Quercus Shrub & $*$ & $*$ & $*$ & $*$ & \\
\hline Rhododendron Shrub & & $*$ & & & $*$ \\
\hline Robinia DBF & & $*$ & & $*$ & $*$ \\
\hline Salix DBF & & $*$ & & $*$ & $*$ \\
\hline Salix Shrub & & $*$ & $*$ & $*$ & $*$ \\
\hline Sasa Shrub & $*$ & $*$ & $*$ & $*$ & $*$ \\
\hline Thuja ECF & & $*$ & & & \\
\hline Thujopsis ECF & & $*$ & & & $*$ \\
\hline Tsuga ECF & $*$ & $*$ & $*$ & & $*$ \\
\hline Ulmus DBF & & $*$ & & & $*$ \\
\hline Upland field & & $*$ & & $*$ & $*$ \\
\hline Urban builtup & & $*$ & $*$ & $*$ & $*$ \\
\hline Water & & $*$ & $*$ & $*$ & $*$ \\
\hline Wetland Herb & $*$ & $*$ & $*$ & & $*$ \\
\hline Zanthoxylum DBF & & $*$ & & & \\
\hline Zelkova DBF & & $*$ & & $*$ & $*$ \\
\hline Zoysia Herb & & & & & $*$ \\
\hline Total classes & 19 & 41 & 25 & 26 & 36 \\
\hline
\end{tabular}

DBF: Deciduous Broadleaf Forest; DCF: Deciduous Conifer Forest

ECF: Evergreen Conifer Forest; EBF: Evergreen Broadleaf Forest

The ground truth data, polygons representing homogeneous land cover and plant community types of around 1ha size, were collected with reference to extant vegetation survey maps (1:25,0000 scale) produced from extensive field surveys between 2012 to 2020, and visual interpretation of time-lapse images available in the Google Earth by local experts in plant ecology and vegetation sciences. The distribution of ground truth data in the study sites has been shown in Figure 2. 


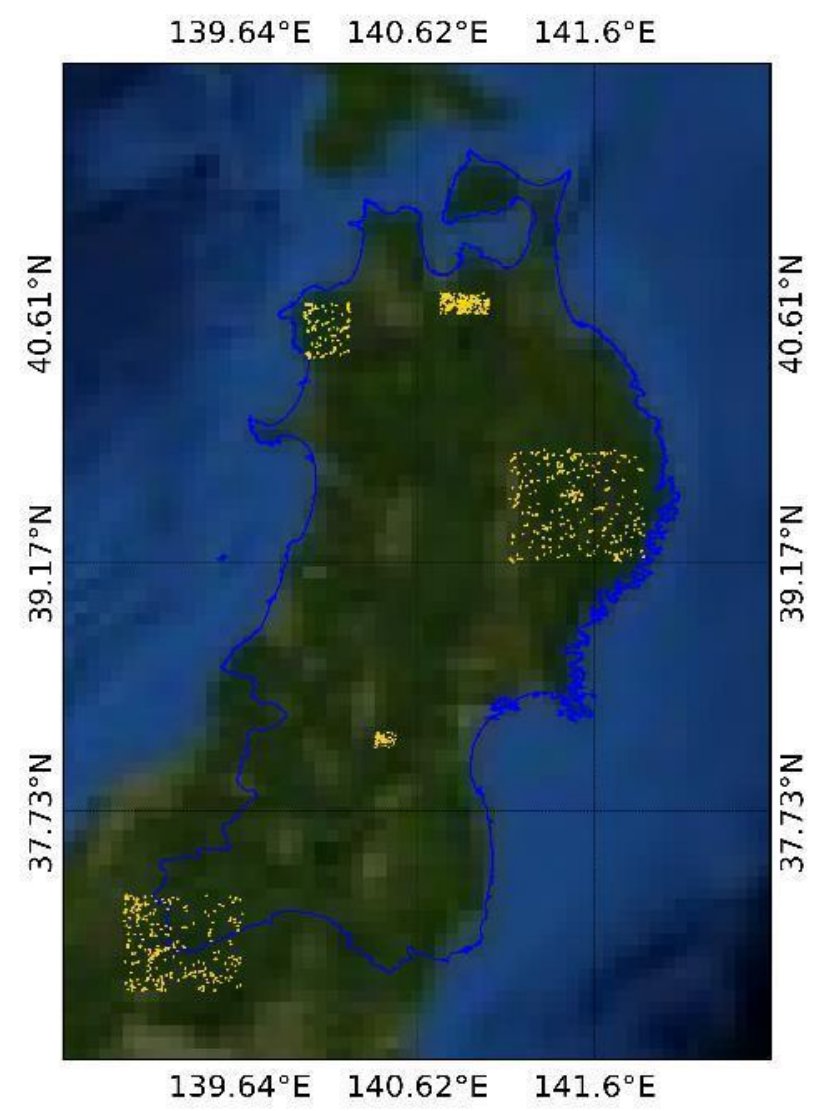

Figure 2. The distribution of ground truth data (yellow color) collected in the research.

\subsection{Processing of satellite data}

We acquired all Level-1C product images collected by Sentinel-2 mission satellites (Sentinel-2A and 2B) for the study sites between 2017-2019. The Sentinel-2 mission satellites collect optical imagery at high spatial resolution $(10-60 \mathrm{~m})$ in visible, near infrared, and short-wave wavelengths at a frequency of five days (Drusch et al., 2012). The images were processed for cloud masking and ten spectral bands (blue, green, red, red edge 1-3, near infrared, mid infrared, and shortwave infrared 1-2) were extracted. For each scene, twelve vegetation indices (as shown in Table 2) were also calculated. The spectral and spectral-indices images were composited by computing monthly median values. In this manner, we generated 264 features (22 spectral and spectral-indices $\times 12$ months) altogether for machine learning, classification, and mapping. 
Table 2. List of vegetation indices utilized in the research. Blue (B, Band 2), Green (G, Band 3), Red (R, Band 4), Red edge1 (RE1, Band 5), Red edge3 (RE3, Band 7), and Near infrared (N, Band 8) were used for calculating the vegetation indices.

\begin{tabular}{lcc}
\hline Spectral indices & Formula & References \\
\hline Atmospherically Resistant Vegetation Index (ARVI) & $\frac{N-R-(R-B)}{N+R-(R-B)}$ & Kaufman and Tanre, 1992 \\
Enhanced Vegetation Index (EVI) & $2.5 \times \frac{N-R}{(N+6 \times R-7.5 \times B)+1}$ & Huete et al., 2002 \\
Green Atmospherically Resistant Index (GARI) & $\frac{N-(G-1.7 \times(B-R))}{N+(G-1.7 \times(B-R))}$ & Gitelson et al., 1996 \\
Green Leaf Index (GLI) & $\frac{(G-R)+(G-B)}{(2 * G)+R+B}$ & Louhaichi et al., 2001 \\
Green Red Vegetation Index (GRVI) & $\frac{G-R}{G+R}$ & Falkowski et al., 2005 \\
Modified Red Edge Simple Ratio (MRESR) & $\frac{R E 3-B}{R E 1-B}$ & Sims and Gamon, 2002 \\
Modified Soil Adjusted Vegetation Index (MSAVI) & $\frac{2 N+1-\sqrt{(2 N+1)^{2}-8(N-R)}}{2}$ Qi et al., 1994 \\
Normalized Difference Vegetation Index (NDVI) & $\frac{N-R}{N+R}$ & Rouse et al., 1974 \\
Optimized Soil Adjusted Vegetation Index (OSAVI) & $\frac{(N-R)}{(N+R+0.16)}$ & Rondeaux et al., 1996 \\
Red Edge Normalized Difference Vegetation Index \\
(RENDVI)
\end{tabular}

\subsection{Machine learning and classification}

We employed Gradient Boosting Decision Trees (GBDT) classifier implemented by XGBoost, an efficient and optimized distributed gradient boosting library (https://github.com/dmlc/xgboost) for the supervised classification of Sentinel-2 images as it can handle large data volume with Compute Unified Device Architecture (CUDA) computations. We implemented a train-test split method for fine tuning of input features and model parameters. Classification accuracy metrics (Accuracy, Kappa coefficient, F1score, Recall, and Precision) were utilized for quantitative evaluation. For this method, ground truth data were shuffled and randomly splitted into train (75\%) and test (25\%) sets. The GBDT model was trained on the training data, whereas test data was utilized for fine tuning the parameters of the model. The GBDT model established in this was utilized for prediction and mapping of land cover and plant community types separately for each site.

\section{Results and Discussion}

\subsection{Model test results}

The model test results obtained from the machine learning (GBDT classifier) of multitemporal Sentinel-2 images have been shown using the confusion matrix figures (Figures 3-5) for three sites (Hakkoda, Zao, and Shirakami). Due to many classes involved, classwise accuracy tables (Tables 3 and 4 ) have been shown for two sites (Oze and Kitakami). 




Figure 3. Confusion matrix obtained for Hakkoda site.

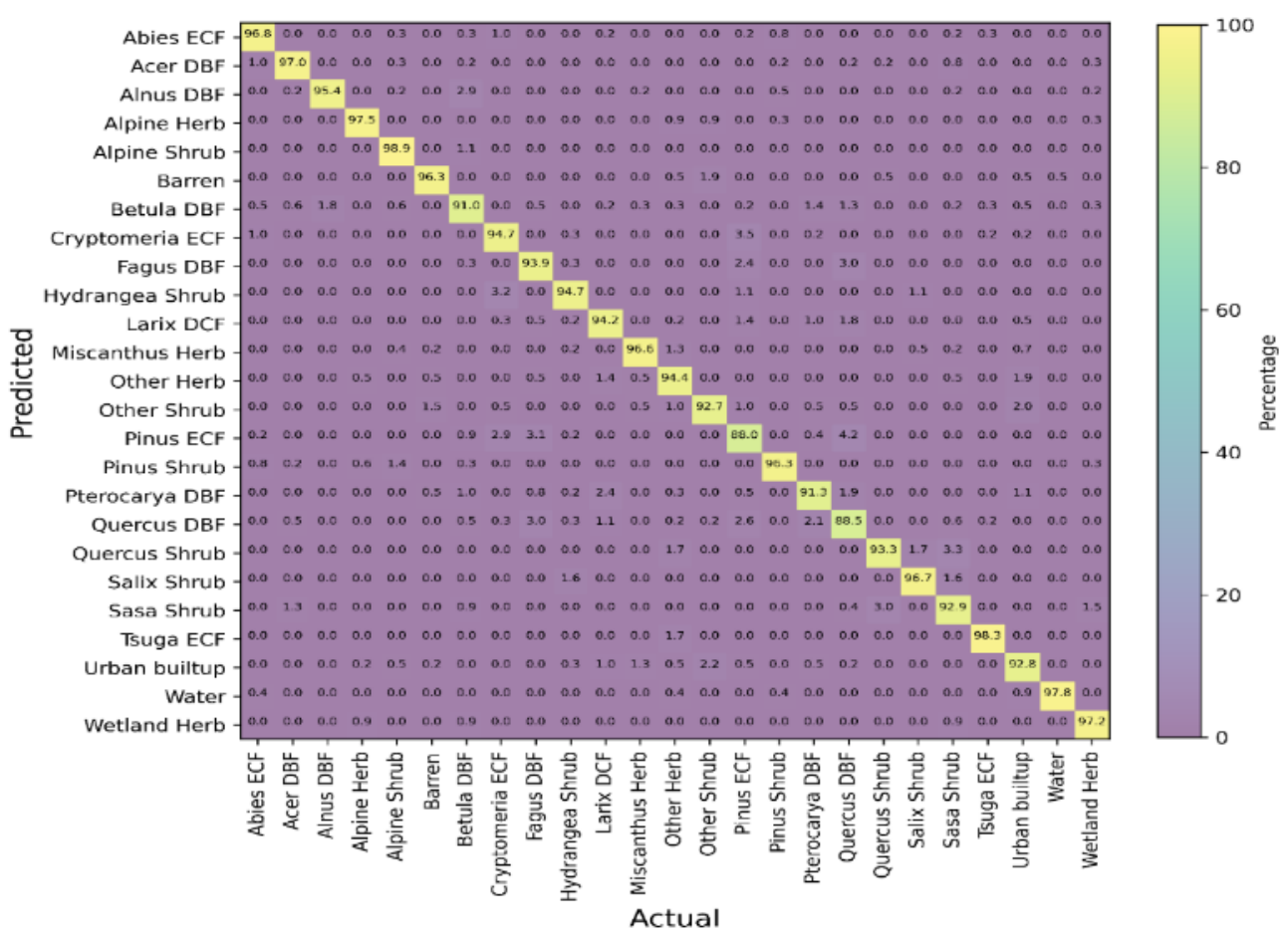

Figure 4. Confusion matrix obtained for Zao site. 


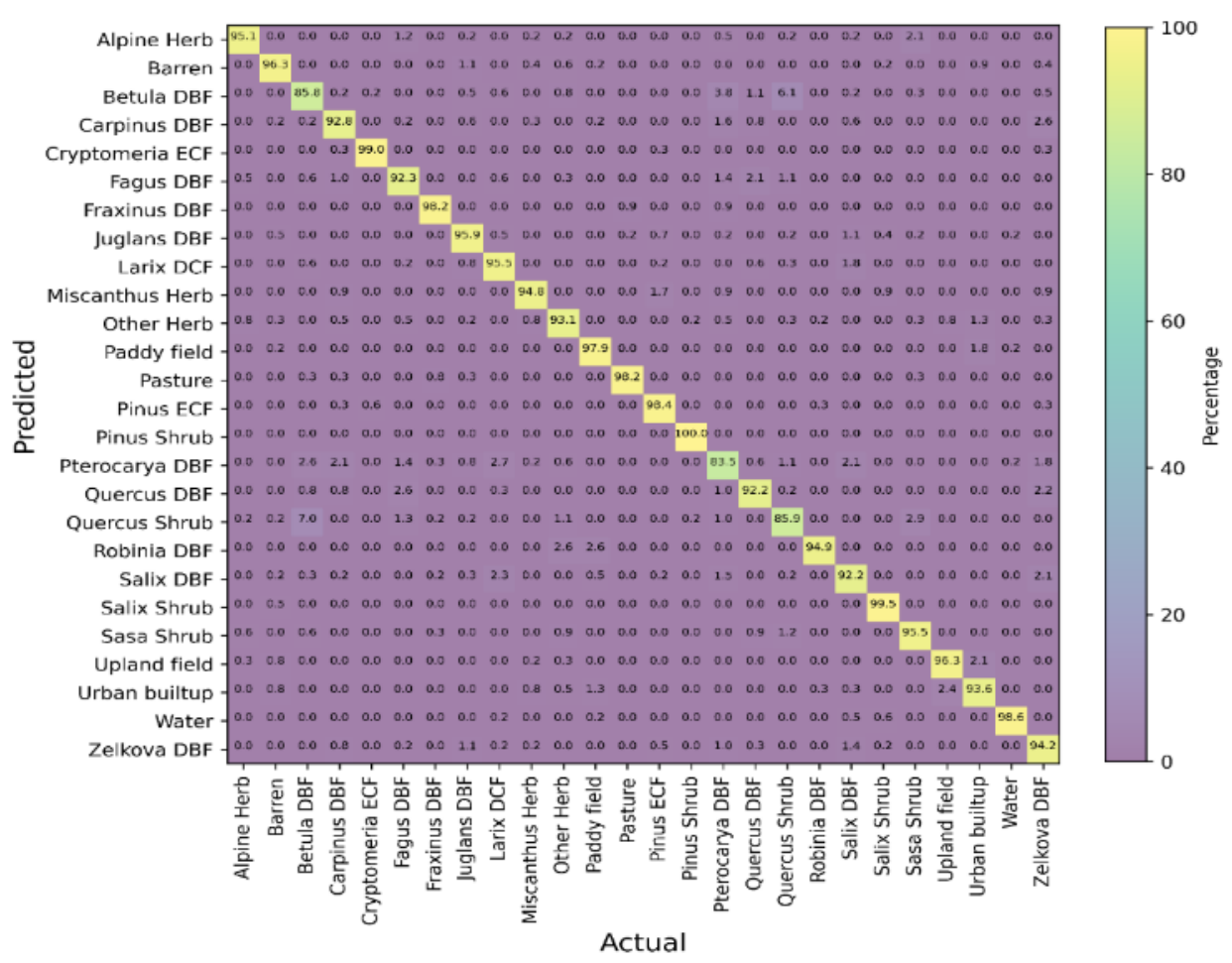

Figure 5. Confusion matrix obtained for Shirakami site.

Table 3. Class-wise accuracy obtained for Oze site.

\begin{tabular}{|l|r|r|r|r|r|}
\hline Classes & Accuracy & Kappa & F1-score & Recall & Precision \\
\hline Abies ECF & 0.995 & 0.891 & 0.955 & 0.84 & 0.894 \\
\hline Acer DBF & 0.996 & 0.927 & 0.915 & 0.944 & 0.929 \\
\hline Alnus DBF & 0.986 & 0.716 & 0.736 & 0.712 & 0.724 \\
\hline Alpine Herb & 0.996 & 0.927 & 0.921 & 0.936 & 0.929 \\
\hline Bamboo EBF & 1.000 & 1.000 & 1.000 & 1.000 & 1.000 \\
\hline Barren & 0.994 & 0.890 & 0.883 & 0.904 & 0.893 \\
\hline Betula DBF & 0.988 & 0.766 & 0.785 & 0.760 & 0.772 \\
\hline Carpinus DBF & 0.995 & 0.904 & 0.885 & 0.928 & 0.906 \\
\hline Cryptomeria ECF & 0.991 & 0.820 & 0.861 & 0.792 & 0.825 \\
\hline Euptelea DBF & 0.994 & 0.882 & 0.875 & 0.896 & 0.885 \\
\hline Fagus DBF & 0.987 & 0.760 & 0.723 & 0.816 & 0.767 \\
\hline Fraxinus DBF & 0.998 & 0.968 & 0.947 & 0.992 & 0.969 \\
\hline Hydrangea Shrub & 0.985 & 0.718 & 0.701 & 0.752 & 0.726 \\
\hline Juglans DBF & 0.991 & 0.832 & 0.797 & 0.88 & 0.837 \\
\hline Larix DCF & 0.994 & 0.877 & 0.914 & 0.848 & 0.880 \\
\hline Miscanthus Herb & 0.993 & 0.870 & 0.866 & 0.88 & 0.873 \\
\hline Other Herb & 0.996 & 0.929 & 0.943 & 0.92 & 0.931 \\
\hline Other Shrub & 0.99 & 0.797 & 0.829 & 0.776 & 0.802 \\
\hline Paddy field & 0.996 & 0.915 & 0.949 & 0.888 & 0.917 \\
\hline Pasture & 0.995 & 0.903 & 0.891 & 0.920 & 0.906 \\
\hline Pinus ECF & 0.991 & 0.823 & 0.831 & 0.824 & 0.827 \\
\hline Pinus Shrub & 0.999 & 0.782 & 0.643 & 1.000 & 0.783 \\
\hline Populus DBF & 0.998 & 0.955 & 0.952 & 0.960 & 0.956 \\
\hline Pterocarya DBF & 0.988 & 0.760 & 0.772 & 0.760 & 0.766 \\
\hline
\end{tabular}




\begin{tabular}{|l|l|l|l|l|l|} 
Quercus DBF & 0.989 & 0.785 & 0.781 & 0.800 & 0.791 \\
\hline Quercus Shrub & 0.990 & 0.799 & 0.862 & 0.752 & 0.803 \\
\hline Rhododendron Shrub & 0.996 & 0.851 & 0.812 & 0.897 & 0.852 \\
\hline Robinia DBF & 0.998 & 0.967 & 0.961 & 0.976 & 0.968 \\
\hline Salix DBF & 0.994 & 0.879 & 0.893 & 0.872 & 0.883 \\
\hline Salix Shrub & 0.994 & 0.879 & 0.868 & 0.896 & 0.882 \\
\hline Sasa Shrub & 0.996 & 0.917 & 0.927 & 0.912 & 0.919 \\
\hline Thuja ECF & 0.909 & 0.810 & 0.821 & 0.808 & 0.815 \\
\hline Thujopsis ECF & 0.992 & 0.833 & 0.851 & 0.824 & 0.837 \\
\hline Tsuga ECF & 0.992 & 0.845 & 0.821 & 0.880 & 0.849 \\
\hline Ulmus DBF & 0.998 & 0.956 & 0.938 & 0.976 & 0.957 \\
\hline Upland field & 0.996 & 0.918 & 0.920 & 0.920 & 0.920 \\
\hline Urban builtup & 0.997 & 0.937 & 0.966 & 0.912 & 0.938 \\
\hline Water & 1.000 & 0.992 & 0.992 & 0.992 & 0.992 \\
\hline Wetland Herb & 0.998 & 0.954 & 0.975 & 0.936 & 0.955 \\
\hline Zanthoxylum DBF & 0.997 & 0.904 & 0.886 & 0.925 & 0.905 \\
\hline Zelkova DBF & 0.993 & 0.855 & 0.869 & 0.848 & 0.858 \\
\hline
\end{tabular}

Table 4. Class-wise accuracy obtained for Kitakami site.

\begin{tabular}{|c|c|c|c|c|c|}
\hline Classes & Accuracy & Kappa & F1-score & Recall & Precision \\
\hline Abies ECF & 0.995 & 0.932 & 0.941 & 0.929 & 0.935 \\
\hline Alnus DBF & 0.987 & 0.811 & 0.852 & 0.786 & 0.818 \\
\hline Alpine Herb & 0.998 & 0.964 & 0.962 & 0.970 & 0.966 \\
\hline Alpine Shrub & 0.996 & 0.944 & 0.943 & 0.948 & 0.946 \\
\hline Bamboo EBF & 1.000 & 0.850 & 0.755 & 0.974 & 0.851 \\
\hline Barren & 0.993 & 0.899 & 0.918 & 0.888 & 0.903 \\
\hline Betula DBF & 0.989 & 0.849 & 0.863 & 0.845 & 0.854 \\
\hline Carpinus DBF & 0.996 & 0.946 & 0.924 & 0.974 & 0.948 \\
\hline Cryptomeria ECF & 0.995 & 0.929 & 0.952 & 0.913 & 0.932 \\
\hline Fagus DBF & 0.993 & 0.899 & 0.882 & 0.926 & 0.903 \\
\hline Fraxinus DBF & 0.998 & 0.949 & 0.945 & 0.956 & 0.951 \\
\hline Juglans DBF & 0.988 & 0.826 & 0.821 & 0.845 & 0.833 \\
\hline Larix DCF & 0.995 & 0.927 & 0.935 & 0.924 & 0.930 \\
\hline Miscanthus Herb & 0.991 & 0.868 & 0.895 & 0.852 & 0.873 \\
\hline Other Shrub & 0.998 & 0.831 & 0.774 & 0.901 & 0.833 \\
\hline Paddy field & 0.998 & 0.973 & 0.977 & 0.97 & 0.974 \\
\hline Pasture & 0.998 & 0.971 & 0.971 & 0.974 & 0.972 \\
\hline Picea ECF & 0.999 & 0.752 & 0.613 & 0.974 & 0.752 \\
\hline Pinus ECF & 0.994 & 0.909 & 0.895 & 0.931 & 0.913 \\
\hline Pinus Shrub & 1.000 & 0.913 & 0.840 & 1.000 & 0.913 \\
\hline Pterocarya DBF & 0.992 & 0.885 & 0.895 & 0.883 & 0.889 \\
\hline Quercus DBF & 0.988 & 0.820 & 0.877 & 0.782 & 0.827 \\
\hline Rhododendron Shrub & 1.000 & 0.976 & 0.953 & 1.000 & 0.976 \\
\hline Robinia DBF & 0.996 & 0.840 & 0.776 & 0.92 & 0.842 \\
\hline Salix DBF & 0.993 & 0.885 & 0.913 & 0.865 & 0.889 \\
\hline Salix Shrub & 0.997 & 0.894 & 0.855 & 0.94 & 0.895 \\
\hline
\end{tabular}




\begin{tabular}{|l|l|l|l|l|l|} 
Sasa Shrub & 0.999 & 0.955 & 0.937 & 0.974 & 0.955 \\
\hline Thujopsis ECF & 0.994 & 0.921 & 0.927 & 0.921 & 0.924 \\
\hline Tsuga ECF & 0.996 & 0.947 & 0.952 & 0.946 & 0.949 \\
\hline Ulmus DBF & 0.997 & 0.899 & 0.858 & 0.949 & 0.901 \\
\hline Upland field & 0.994 & 0.907 & 0.925 & 0.896 & 0.910 \\
\hline Urban builtup & 0.995 & 0.927 & 0.925 & 0.934 & 0.930 \\
\hline Water & 0.999 & 0.979 & 0.978 & 0.982 & 0.980 \\
\hline Wetland Herb & 0.996 & 0.937 & 0.941 & 0.938 & 0.939 \\
\hline Zelkova DBF & 0.991 & 0.878 & 0.876 & 0.888 & 0.882 \\
\hline Zoysia Herb & 0.999 & 0.792 & 0.670 & 0.969 & 0.792 \\
\hline Zoysia Herb & 0.999 & 0.792 & 0.670 & 0.969 & 0.792 \\
\hline
\end{tabular}

The classification accuracy matrices obtained for all study sites have been summarized in Table 5. The classification accuracy in terms of kappa coefficient varied from $87 \%$ in Oze site with 41 classes to $95 \%$ in Hakkoda site with 19 classes.

Table 5. Summary of classification accuracy metrics obtained for all sites.

\begin{tabular}{|c|c|c|c|c|c|c|}
\hline Sites & Classes & Accuracy & Kappa & F1-score & Recall & Precision \\
\hline Hakkoda & 19 & 0.950 & 0.947 & 0.950 & 0.950 & 0.950 \\
\hline Zao & 25 & 0.941 & 0.937 & 0.941 & 0.941 & 0.941 \\
\hline Oze & 41 & 0.873 & 0.870 & 0.873 & 0.873 & 0.873 \\
\hline Shirakami & 26 & 0.938 & 0.935 & 0.938 & 0.938 & 0.938 \\
\hline Kitakami & 36 & 0.912 & 0.909 & 0.912 & 0.912 & 0.912 \\
\hline
\end{tabular}

\subsection{Land Cover and Plant Community Maps}

The Land Cover and Plant Community Maps produced in this research have been shown in Figures 6-10. These maps demonstrate the extent and distribution of land cover and plant community types clearly for the study sites concerned.



Figure 6. 19-class land cover and plant community map of Hakkoda site produced in the research. 


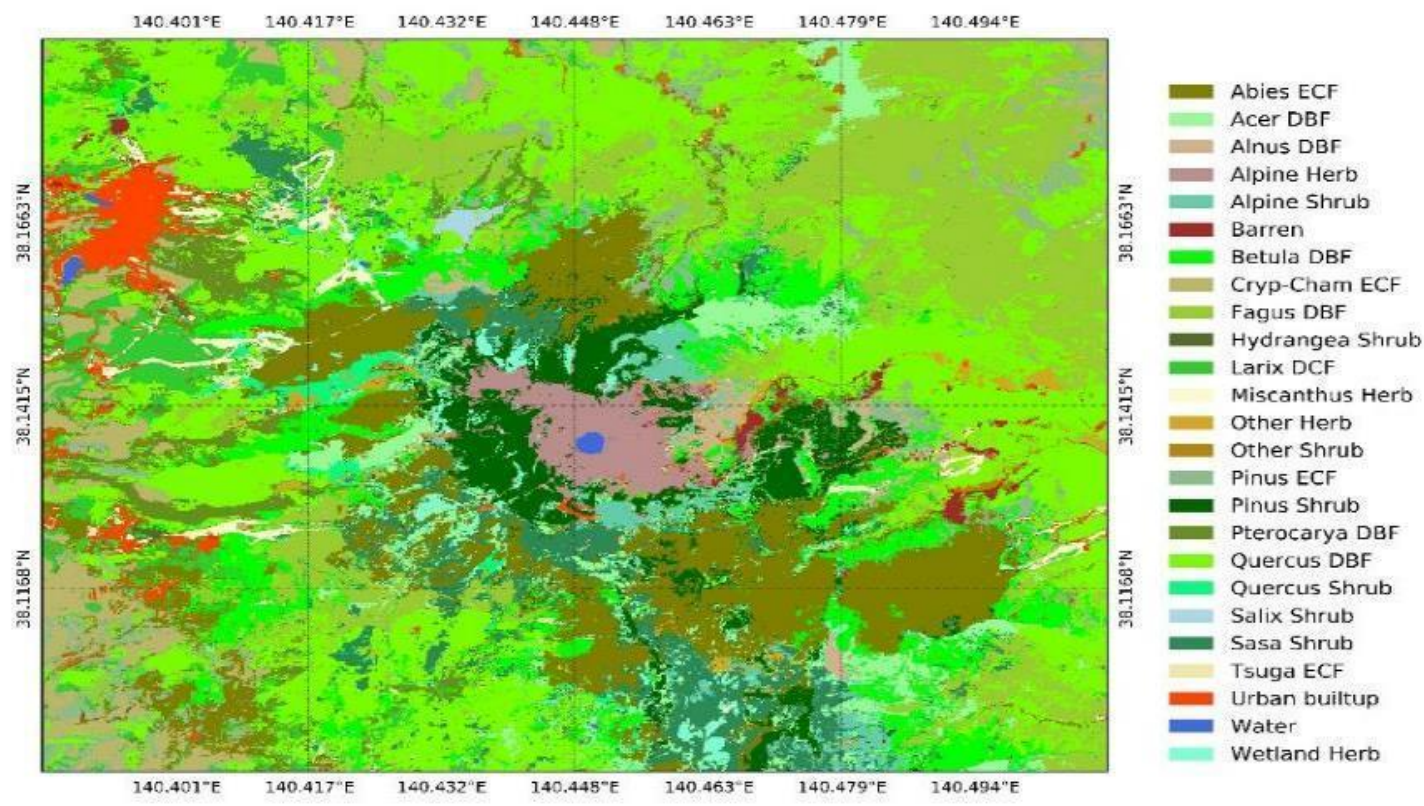

Figure 7. 25-class land cover and plant community map of Zao site produced in the research.

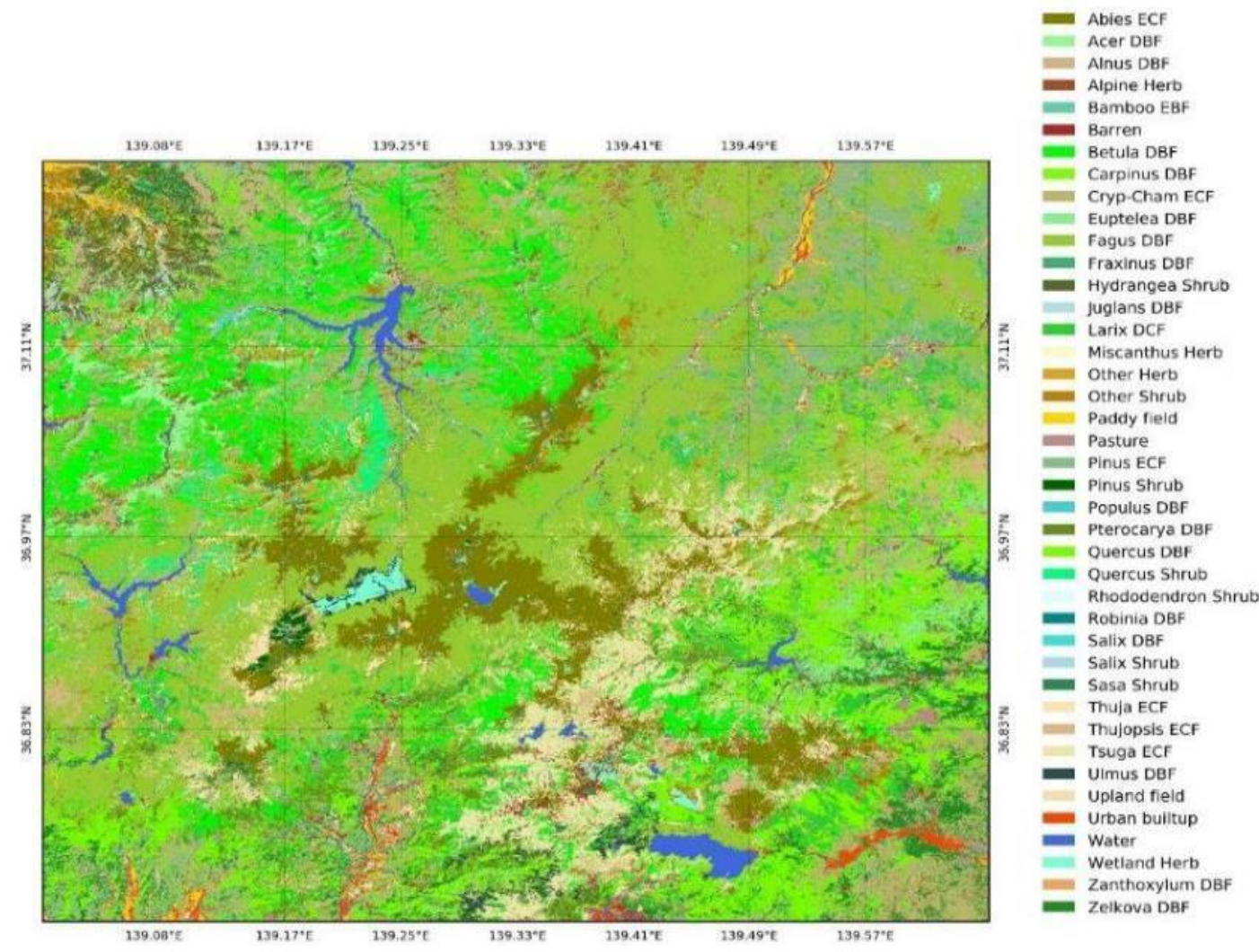

Figure 8. 41-class land cover and plant community map of Oze site produced in the research. 


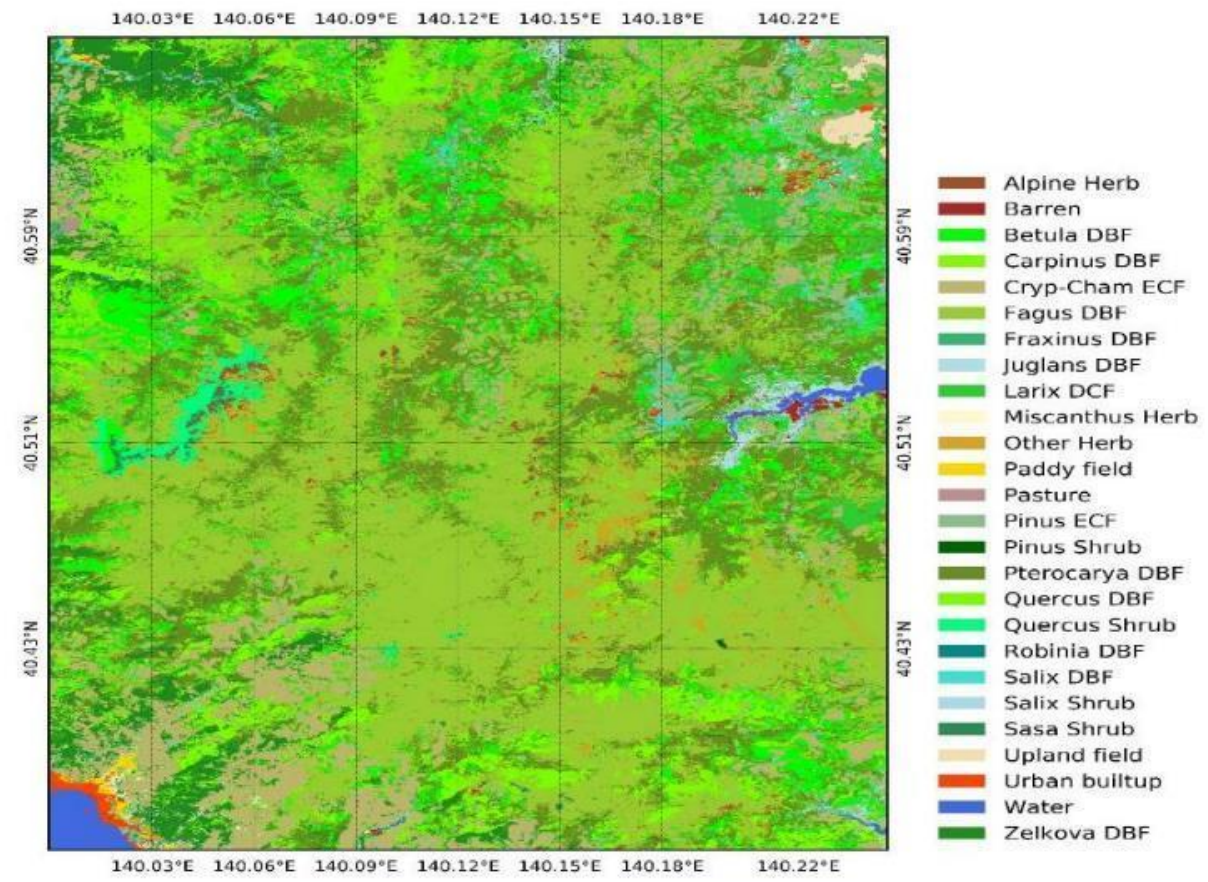

Figure 9. 26-class land cover and plant community map of Shirakami site produced in the research.
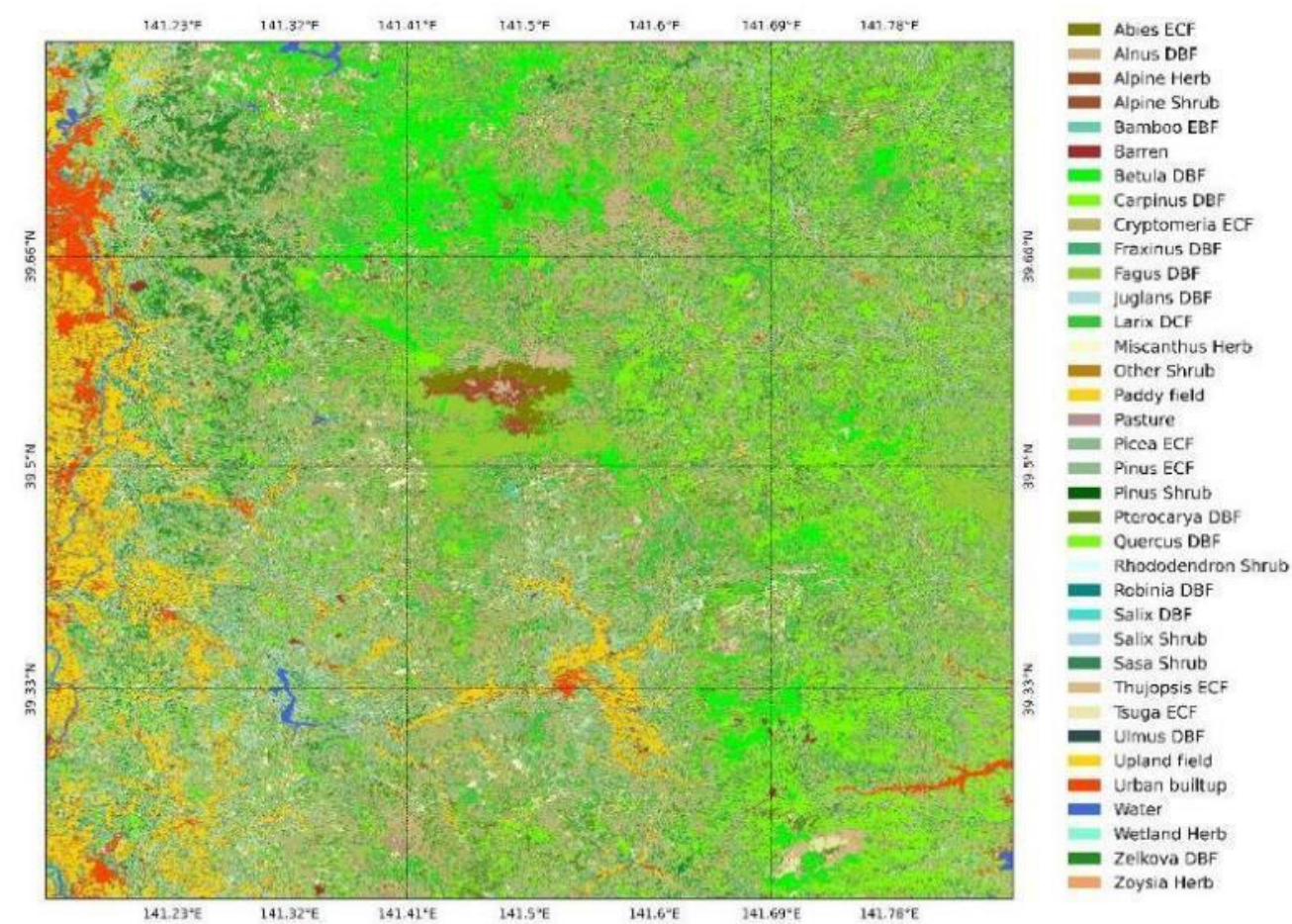

Figure 10. 36-class land cover and plant community map of Kitakami site produced in the research.

Preparation of ground truth data becomes very difficult, time-consuming, and expensive when the heterogeneity and complexity of plant community types increase. Even with the large amounts of high quality ground truth data, classification of satellite images becomes increasingly challenging as the number of classes increases. On the other hand, the characteristic species based phyto-sociological classes (Poore, 1955; Whittaker, 1980; Miyawaki and Fujiwara, 1988) delineated by nationwide vegetation survey is out from automated digital mapping approach as remote sensing signals are mostly governed 
by physical interactions of dominant species rather than characteristic species. Therefore, a right and effective organization of plant communities is essential for operational and broad-scale mapping. In line with this, the Genus-Physiognomy-Ecosystem (GPE) system, developed by Sharma, 2021 for the classification of plant communities from the perspective of satellite remote sensing, was extended in this research for operational mapping of land cover and plant community types collectively.

\title{
4. Conclusions
}

In this research, we presented operational mapping of land cover and plant community types in five study sites in a temperate region in Japan by utilizing multispectral and multi-temporal Sentinel-2. Machine learning based accuracy analysis showed potential of the Sentinel-2 images for the mapping of land cover and plant community types by adopting Genus-Physiognomy-Ecosystem (GPE) system as the kappa coefficient varied from $87 \%$ (41 classes in Oze site) to 95\% (19 classes in Hakkoda site). Still, some misclassifications were detected in some classes such as Betula DBF, Alnus DBF, Fagus DBF, Quercus DBF, Picea ECF, Hydrangea Shrub, and Zoysia Herb particularly in sites associated with many classes. Further increase in the temporal resolution of Sentinel-2 mission satellites images with future launches of Sentinel-2C and 2D satellites is highly expected for improving the classification accuracy of plant communities. Future plan is to expand this methodology for seamless mapping of plant communities in the same region by further increasing the ground truth data.

\begin{abstract}
Author Contributions: R. Sharma conceptualized the research, performed the research, and wrote the manuscript. H. Hirayama assisted in data processing and analysis. M. Yasuda and I. Asai assisted in the organization and collection of groundtruth data. K. Hara supervised the research. All authors have read and agreed to the published version of the manuscript.
\end{abstract}

Funding: The field data was supported by the commissioned research of the Ministry of the Environment, Center for Biodiversity and Asia Air Survey Co., Ltd. This research was partially supported by JSPS Grant-in-Aid for Scientific Research (JP19H04320).

Conflicts of Interest: The authors declare no conflict of interest.

\section{References}

1. Bredenkamp, G.; Chytrý, M.; Fischer, H.S.; Neuhäuslová, Z.; van der Maarel, E. Vegetation Mapping: Theory, Methods and Case Studies: Introduction. Applied Vegetation Science 1998, 1, 162-164.

2. Drusch, M.; Del Bello, U.; Carlier, S.; Colin, O.; Fernandez, V.; Gascon, F.; Hoersch, B.; Isola, C.; Laberinti, P.; Martimort, P.; et al. Sentinel-2: ESA's Optical High-Resolution Mission for GMES Operational Services. Remote Sensing of Environment 2012, 120, 25-36, doi:10.1016/j.rse.2011.11.026.

3. Falkowski, M.J.; Gessler, P.E.; Morgan, P.; Hudak, A.T.; Smith, A.M.S. Characterizing and Mapping Forest Fire Fuels Using ASTER Imagery and Gradient Modeling. Forest Ecology and Management 2005, 217, 129-146, doi:10.1016/j.foreco.2005.06.013.

4. Gitelson, A.A.; Gritz t, Y.; Merzlyak, M.N. Relationships between Leaf Chlorophyll Content and Spectral Reflectance and Algorithms for Non-Destructive Chlorophyll Assessment in Higher Plant Leaves. Journal of Plant Physiology 2003, 160, 271-282, doi:10.1078/0176-1617-00887.

5. Gitelson, A.A.; Kaufman, Y.J.; Merzlyak, M.N. Use of a Green Channel in Remote Sensing of Global Vegetation from EOS-MODIS. Remote Sensing of Environment 1996, 58, 289-298, doi:10.1016/S0034-4257(96)00072-7.

6. Hengl, T.; Walsh, M.G.; Sanderman, J.; Wheeler, I.; Harrison, S.P.; Prentice, I.C. Global Mapping of Potential Natural Vegetation: An Assessment of Machine Learning Algorithms for Estimating Land Potential. PeerJ 2018, 6, e5457, doi:10.7717/peerj.5457.

7. Himiyama, Y. Land Use/Cover Changes in Japan: From the Past to the Future. Hydrological Processes 1998, 12, 1995 2001, doi:10.1002/(SICI)1099-1085(19981030)12:13/14<1995::AID-HYP714>3.0.CO;2-C.

8. Hioki, Y. Issues of Nation -Wide Actual Vegetation Maps from the Aspect for Application. Landscape Ecology and Management 2007, 11, 107-112, doi:10.5738/jale.11.107. 
9. Huete, A.; Didan, K.; Miura, T.; Rodriguez, E.P.; Gao, X.; Ferreira, L.G. Overview of the Radiometric and Biophysical Performance of the MODIS Vegetation Indices. Remote Sensing of Environment 2002, 83, 195-213, doi:10.1016/S0034-4257(02)00096-2.

10. Huete, A.R. A Soil-Adjusted Vegetation Index (SAVI). Remote Sensing of Environment 1988, 25, 295-309, doi:10.1016/0034-4257(88)90106-X.

11. Kaufman, Y.J.; Tanre, D. Atmospherically Resistant Vegetation Index (ARVI) for EOS-MODIS. IEEE Trans. Geosci. Remote Sensing 1992, 30, 261-270, doi:10.1109/36.134076.

12. Louhaichi, M.; Borman, M.M.; Johnson, D.E. Spatially Located Platform and Aerial Photography for Documentation of Grazing Impacts on Wheat. Geocarto International 2001, 16, 65-70, doi:10.1080/10106040108542184.

13. Miyawaki, A. A Vegetation-Ecological View of the Japanese Archipelago. Bulletin of the Institute of Environmental Science and Technology 1984, 11, 85-101.

14. Miyawaki, A. Typen von Vegetationskarten Und Ihre Anwendung Fur Die Beurteilung Des Standortes. Map, Journal of the Japan Cartographers Association 1968, 6, 1-9.

15. Miyawaki, A.; Fujiwara, K. Vegetation Mapping in Japan. In Vegetation mapping; Küchler, A.W., Zonneveld, I.S., Eds.; Springer Netherlands: Dordrecht, 1988; pp. 427-441 ISBN 978-94-010-7885-6.

16. MoE Nature Conservation Bureau, Ministry of the Environment of Japan and Asia Air Survey Co., Ltd. The 5th National Survey on the Natural Environment (Vegetation Survey) Report 1999.

17. Murakami T.; Mochizuki S. Vegetation mapping using remotely sensed imagery 2014.

18. Numata, M.; Miyawaki, A.; Itow, D. Natural and Semi-Natural Vegetation in Japan. Blumea 1972, $20,435-496$.

19. Ohno, K. Applications of a Phytosociological Vegetation Map and Its Role for Development with Landscape Ecology. Landscape Ecology and Management 2006, 11, 39-52, doi:10.5738/jale.11.39.

20. Penuelas, J.; Frederic, B.; Filella, I. Semi-Empirical Indices to Assess Carotenoids/Chlorophyll-a Ratio from Leaf Spectral Reflectance. Photosynthetica 1995, 31, 221-230.

21. Poore, M.E.D. The Use of Phytosociological Methods in Ecological Investigations: I. The Braun-Blanquet System. The Journal of Ecology 1955, 43, 226, doi:10.2307/2257132.

22. Qi, J.; Chehbouni, A.; Huete, A.R.; Kerr, Y.H.; Sorooshian, S. A Modified Soil Adjusted Vegetation Index. Remote Sensing of Environment 1994, 48, 119-126, doi:10.1016/0034-4257(94)90134-1.

23. Rondeaux, G.; Steven, M.; Baret, F. Optimization of Soil-Adjusted Vegetation Indices. Remote Sensing of Environment 1996, 55, 95-107, doi:10.1016/0034-4257(95)00186-7.

24. Rouse, J.W.; Haas, R.H.; Schell, J.A.; Deering, D.W. Monitoring Vegetation Systems in the Great Plains with ERTS. NASA special publication 1974, 351, 309.

25. Sharma, R.C. Genus-Physiognomy-Ecosystem (GPE) System for Satellite-Based Classification of Plant Communities. Ecologies 2021, 2, 203-213, doi:10.3390/ecologies2020012.

26. Sims, D.A.; Gamon, J.A. Relationships between Leaf Pigment Content and Spectral Reflectance across a Wide Range of Species, Leaf Structures and Developmental Stages. Remote Sensing of Environment 2002, 81, 337-354, doi:10.1016/S0034-4257(02)00010-X.

27. Su, Y.; Guo, Q.; Hu, T.; Guan, H.; Jin, S.; An, S.; Chen, X.; Guo, K.; Hao, Z.; Hu, Y.; et al. An Updated Vegetation Map of China (1:1000000). Science Bulletin 2020, 65, 1125-1136, doi:10.1016/j.scib.2020.04.004.

28. Whittaker, R.H. Classification of Plant Communities; Springer Netherlands: Dordrecht, 1980; ISBN 978-94-009-91835 .

29. Wulder, M.A.; Coops, N.C.; Roy, D.P.; White, J.C.; Hermosilla, T. Land Cover 2.0. International Journal of Remote Sensing 2018, 39, 4254-4284, doi:10.1080/01431161.2018.1452075. 